\title{
A arte nas escolas-parque de Brasília: concepções do trabalho pedagógico
}

\author{
Rafaella Lira Silva dos Santos de Vasconcelos ${ }^{\mathrm{I}, \mathrm{II}}$ \\ Ingrid Dittrich Wiggers ${ }^{\mathrm{IIII}, \mathrm{IV}}$
}

http://dx.doi.org/10.24109/2176-6681.rbep.101i259.3870

\footnotetext{
Universidade de Brasília (UnB). Brasília, Distrito

Federal, Brasil. E-mail:

<ellaella68@gmail.

com>; $<$ https://orcid. org/0000-0002-3615-0241>.

II Mestre em Educação pela Universidade de Brasília (UnB). Brasília, Distrito Federal, Brasil.

III Universidade de Brasília (UnB). Brasília, Distrito Federal, Brasil. E-mail:<ingridwiggers@ gmail.com $>;<$ https://orcid. org/0000-0001-5412-7021>

IV Doutora em Educação pela Universidade Federal de Santa Catarina (UFSC). Florianópolis, Santa Catarina, Brasil.
}

\section{Resumo}

O artigo objetiva conhecer as concepções do ensino de arte que permeiam o trabalho pedagógico das escolas-parque de Brasília. Por meio de revisão sistemática na produção acadêmica nacional em forma de teses, dissertações, livros e capítulos de livros, foram identificados 18 estudos entre o ano de fundação da primeira escola-parque de Brasília, 1960, e o ano de 2017. Para auxiliar a análise desses estudos, o artigo se baseia em textos de John Dewey e Anísio Teixeira, tendo em vista que seus pensamentos constituíram a gênese das escolas-parque. Na análise, foi possível perceber três concepções do ensino de arte: a) como referência de uma nova perspectiva pedagógica para a educação nacional; b) como elemento entrelaçador de culturas e construtor de uma identidade para a cidade de Brasília; e c) como mediador de autoexpressão, liberdade, resistência e emancipação.

Palavras-chave: ensino de arte; escola-parque; pesquisa da educação. 


\section{Abstract \\ Art in the park schools of Brasilia: conceptions of pedagogical practices}

This article aims to explore the conceptions of art education that permeate the pedagogical work in the park schools of Brasilia. Through a systematic review of national academic production in the form of theses, dissertations, books and book chapters, eighteen relevant studies were identified between 1960 (the year of the foundation of the first park school in Brasilia) and 2017. Texts by John Dewey and Anísio Teixeira, whose thoughts gave shape to these institutions, were used in order to help analyze the aforementioned studies. It was possible to identify three conceptions of art teaching through this analysis: a) as a reference to a new pedagogical perspective for national education; b) as an interlacing element between cultures in order to create an identity for the city of Brasilia and; c) as a mediator of self-expression, freedom, resistance and emancipation.

Keywords: park schools; research on education; teaching of art.

\section{Resumen}

El arte en las escuelas-parque de Brasilia: concepciones del trabajo pedagógico

Este artículo pretende conocer las concepciones de la enseñanza del arte que impregnan el trabajo pedagógico en las escuelas-parque de Brasilia. Por medio de una revisión sistemática de la producción académica nacional en forma de tesis, disertaciones, libros y capítulos de libros, fueron identificados 18 estudios entre el año de la fundación de la primera escuela-parque de Brasilia, 1960, y el año de 2017. Para auxiliar el análisis de estos estudios, abordamos los textos de John Dewey y Anísio Teixeira, considerando que sus pensamientos constituían la génesis de estas instituciones. En el análisis de las producciones, fue posible identificar tres concepciones de la enseñanza del arte: a) como referencia de una nueva perspectiva pedagógica para la educación nacional; b) como elemento de interconexión de culturas y constructor de una identidad para la ciudad de Brasilia; y c) como mediador de la autoexpresión, libertad, resistencia y emancipación.

Palabras clave: enseñanza del arte; escuela-parque; investigación de la educación. 


\section{O início de um plano para a educação da nova capital brasileira}

O idealizador das escolas-parque foi o educador baiano Anísio Teixeira (1900-1971), um homem inquieto e inventivo que deixou um legado ainda sujeito a análises. Em meados do século passado, exercendo a função de diretor do Instituto Nacional de Estudos e Pesquisas Educacionais (Inep), foi convidado a elaborar o Plano de Construções Escolares de Brasília (Teixeira, 1961). Nele, teve a oportunidade de vislumbrar um sistema educacional que seria um "marco zero" não apenas para a nova capital do País, mas para toda a educação brasileira.

Antes de consumar o Plano de Construções Escolares de Brasília, no início da década de 1960, o educador já havia liderado outro projeto ousado, no bairro da Liberdade, na cidade de Salvador, em 1950: o Centro Educacional Carneiro Ribeiro, conhecido como Escola-Parque da Bahia. Em meio à pobreza e à violência da localidade, concebeu a ideia de que a educação se materializa em uma prática democrática, pautada na integralidade da formação dos indivíduos para a sociedade moderna. Dessa forma, as transformações sociais deveriam ser pensadas com base na educação, pois somente assim seria possível uma sociedade justa, igualitária em oportunidades e compatível com o desenvolvimento político, econômico, social e cultural que se pretendia a partir dos fenômenos da industrialização. A inobservância de uma educação para essa nova sociedade, segundo o próprio Teixeira (1959), levaria a nenhum outro lugar, senão ao caos.

Os horizontes de Teixeira foram ampliados pelas observações e reflexões que pôde formular em duas viagens que fez, uma à Europa, em 1925, e outra aos Estados Unidos, em 1927. Segundo Cardoso (2013), nessas oportunidades, o educador conheceu outras perspectivas educacionais, que considerou de cunho moderno, democrático e humanista. Essas perspectivas instigaram Teixeira a rever sua maneira de pensar a educação no Brasil. Em uma segunda viagem aos Estados Unidos, em 1928, aprofundou-se nos estudos acerca das obras do filósofo e educador norte-americano John Dewey (1859-1952), que se tornou seu maior referencial. Dewey pensava a educação como uma prática orgânica para a vida humana, pois não acreditava ser possível separar vida e educação. Para estruturar a integralidade desse pensamento, o cerne da pedagogia deweyana estava alicerçado na experiência contínua e significativa para o indivíduo e para sua vida em comunidade (Dewey, 2011). Desse modo, razão e sensibilidade, bem como conhecimentos científicos e práticas experimentadas pelos seres humanos, não representavam oposições ou dicotomias, mas complementaridades.

Inspirado por essa perspectiva filosófica e pelo trabalho desenvolvido no bairro da Liberdade, em Salvador, e motivado pela visão progressista do então Presidente Juscelino Kubitschek, Teixeira concebeu o sistema educacional de Brasília. Sua proposta contemplava os Centros de Educação Elementar, em que estavam integrados os jardins de infância, as escolasclasse e as escolas-parque; os Centros de Educação Média; e a Universidade de Brasília (Teixeira, 1961). O projeto previa, inicialmente, a construção 
de 28 escolas-parque; no entanto, até os dias de hoje, apenas 5 foram implantadas (210/211 Sul, 307/308 Sul, 313/314 Sul, 210/211 Norte, 303/304 Norte) para o atendimento de todas as escolas-classe de Brasília e algumas escolas das chamadas regiões administrativas do Distrito Federal. ${ }^{1} \mathrm{~A}$ ideia de Anísio Teixeira era ajustada ainda ao plano urbanístico da cidade, delineado por Lúcio Costa, que esquematizou a habitação da capital em quadras. Dessa forma, no que tange à educação elementar, cada unidade deveria ter um jardim de infância e uma escolaclasse. Já as escolas-parque deveriam estar situadas estrategicamente para atender a um grupo de quatro quadras.

O funcionamento das escolas-classe e das escolas-parque ocorria em turnos opostos, e o trabalho estava conectado de modo que o programa de uma dialogasse com o da outra. Para viabilizar esse arranjo pedagógico, as escolas-parque dispunham de salas de aula, oficinas, laboratório, ambientes para atividades artísticas, auditório, biblioteca, piscinas, refeitório, quadras de esportes e jardins. Essa disposição contrapunha a ideia tradicional de escolas e salas de aula, pois proporcionaria aos estudantes uma educação integral não apenas no sentido de tempo, mas essencialmente no aspecto formativo. Além disso, a estrutura escolar deveria estar ligada à cidade e à sociedade, propondo que a escola fosse como uma universidade para a infância (Teixeira, 1959).

Nessa conjuntura, o ensino de arte na nova capital passou a ser compreendido como elemento essencial para o desenvolvimento cognitivo e social das crianças, que possibilitaria e fortaleceria a ideia de uma educação plena com experiências reais (Dewey, 2010), ou seja, aquelas experiências que se tornam significativas, contínuas, que fazem parte de nossa memória e que nos ajudam com o processo de aprendizagem diante de novas situações da vida. Esses aspectos se viabilizariam com a organização e a qualidade das experiências pedagógicas propostas (Dewey, 2011). Por isso, todo o aparato educativo envolvendo as escolas-parque de Brasília deveria estar interligado e articulado para trilhar essa nova perspectiva educacional.

Considerando a expressividade desse projeto e a necessidade de um mapeamento teórico que coloque em diálogo diferentes perspectivas, este artigo tem o objetivo de conhecer as concepções do ensino de arte que permeiam o trabalho pedagógico nas escolas-parque de Brasília.

\section{Percurso metodológico}

Este estudo partiu da revisão sistemática da literatura em forma de teses, dissertações, livros e capítulos de livros com recorte temporal entre 1960, ano de fundação da primeira escola-parque de Brasília, e 2017. Segundo Tranfield, Denyer e Smart (2003), esse modelo de pesquisa permite que o investigador mapeie e avalie o território intelectual efetivo e tenha condições de problematizar as redes de conhecimento já existentes. Desse modo, torna-se viável transcender a simples agregação e reprodução de resumos das descobertas do trabalho de pesquisa qualitativa para alcançar
Ressaltamos que, a partir de 2013, foram construídas duas escolas denominadas escolas-parque contemporâneas, nas regiões administrativas de Ceilândia e Brazlândia. Apesar de significarem um importante passo, considerando as possibilidades do ideário de Teixeira, elas têm uma proposta diferente da educação elementar e não compõem o escopo da nossa revisão. 
insights originais, bem como novos modelos ou teorias conceituais que podem servir de evidências para intervenções futuras (Rapley; Rees, 2018).

Para estruturar esse percurso, utilizamos a sequência de seis passos sugerida por Soni e Kodali (2011). Iniciamos com a definição do problema de pesquisa; estabelecemos a estratégia do estudo mediante a escolha das bases de dados, do recorte temporal e dos termos de busca; fixamos os critérios para exclusão de trabalhos; selecionamos os estudos; constituímos a análise das fontes e agregamos características qualitativas do processo de análise dos estudos selecionados para a revisão sistemática; e, por fim, apresentamos os resultados, buscando introduzir um novo conhecimento a partir do diálogo estabelecido por meio das leituras selecionadas. Ressalve-se que o quinto passo, que se refere à análise qualitativa das fontes, foi, de modo complementar, orientado pelas propostas metodológicas do trabalho de Cardoso et al. (2017), buscando aprofundar essa dimensão interpretativa. O Quadro 1 detalha essa aplicação.

\section{Quadro 1 - Aplicação da metodologia de revisão sistemática da literatura com base em Soni e Kodali (2011)}

\begin{tabular}{|c|c|c|}
\hline Passos & Descrição & Finalidade \\
\hline $\begin{array}{l}\text { 1. Definição do } \\
\text { problema de } \\
\text { pesquisa }\end{array}$ & $\begin{array}{l}\text { Problema de pesquisa } \\
\text { Quais as concepções do ensino } \\
\text { de arte que permeiam o trabalho } \\
\text { pedagógico nas escolas-parque de } \\
\text { Brasília? }\end{array}$ & $\begin{array}{l}\text { Examinar as } \\
\text { concepções do } \\
\text { ensino de arte nas } \\
\text { escolas-parque de } \\
\text { Brasília. }\end{array}$ \\
\hline $\begin{array}{l}\text { 2. Definição da } \\
\text { estratégia de } \\
\text { pesquisa }\end{array}$ & $\begin{array}{l}\text { Horizonte de tempo } \\
\text { De } 1960 \text { a } 2017 . \\
\text { Bases de pesquisas } \\
\text { Biblioteca Digital Brasileira de } \\
\text { Teses e Dissertações (BDTD) e o } \\
\text { Pergamum do site de consultas } \\
\text { ao acervo da Biblioteca Central } \\
\text { da Universidade de Brasília (BCE/ } \\
\text { UnB). } \\
\text { Identificação de estudos } \\
\text { Busca de teses, dissertações, livros } \\
\text { e capítulos de livros com termos } \\
\text { clássicos sobre o tema (no título, } \\
\text { nas palavras-chave, no resumo } \\
\text { e na introdução): escola parque, } \\
\text { escolasparque, escola-parque e } \\
\text { escolas-parque.* }\end{array}$ & $\begin{array}{l}\text { Abranger o período } \\
\text { entre o ano de } \\
\text { fundação da primeira } \\
\text { escola-parque de } \\
\text { Brasília, 1960, e } 2017 .\end{array}$ \\
\hline $\begin{array}{l}\text { 3. Definição } \\
\text { de critérios de } \\
\text { exclusão }\end{array}$ & $\begin{array}{l}\text { Critérios de exclusão } \\
\text { Todos os trabalhos que não } \\
\text { contribuíam para o exame das } \\
\text { concepções do ensino de arte nas } \\
\text { escolas-parque de Brasília. }\end{array}$ & $\begin{array}{l}\text { Evitar trabalhos que } \\
\text { não convergiam para o } \\
\text { escopo da pesquisa. }\end{array}$ \\
\hline
\end{tabular}


(conclusão)

\begin{tabular}{|l|l|l|}
\multicolumn{1}{|c|}{ Passos } & \multicolumn{1}{|c|}{ Descrição } & \multicolumn{1}{c|}{ Finalidade } \\
\hline $\begin{array}{l}\text { 4. Seleção de } \\
\text { estudos }\end{array}$ & $\begin{array}{l}\text { Critérios de seleção } \\
\text { Estudos que cooperem para o } \\
\text { mapeamento das concepções do } \\
\text { ensino de arte nas escolas-parque } \\
\text { de Brasília. }\end{array}$ & $\begin{array}{l}\text { Selecionar trabalhos } \\
\text { que abordem as } \\
\text { concepções do } \\
\text { ensino de arte nas } \\
\text { escolas-parque de } \\
\text { Brasília. }\end{array}$ \\
\hline $\begin{array}{l}\text { 5. Análise dos } \\
\text { estudos }\end{array}$ & $\begin{array}{l}\text { Elementos para análise } \\
\text { Leituras integrais, fichamentos } \\
\text { descritivos e interpretativos, } \\
\text { estudos das similaridades e } \\
\text { articulações das obras revisadas, } \\
\text { considerando o aporte teórico. }\end{array}$ & $\begin{array}{l}\text { Ampliar a } \\
\text { compreensão } \\
\text { a respeito das } \\
\text { concepções do } \\
\text { ensino de arte nas } \\
\text { escolasparque de } \\
\text { Brasília. }\end{array}$ \\
\hline $\begin{array}{l}\text { 6. Apresentação } \\
\text { dos resultados }\end{array}$ & $\begin{array}{l}\text { Resultado } \\
\text { Elaboração de eixos } \\
\text { interpretativos a partir das } \\
\text { leituras transversais dos textos e } \\
\text { dos conhecimentos produzidos. }\end{array}$ & $\begin{array}{l}\text { Apresentar os enten- } \\
\text { de arte que permeiam } \\
\text { o trabalho pedagógico } \\
\text { nas escolas-parque de } \\
\text { Brasília. }\end{array}$ \\
\hline
\end{tabular}

Fonte: Elaboração própria baseada em dados de Soni e Kodali (2011).

* O uso de diferentes termos se deve à falta de consenso na escrita deles. Assim, os estudos podem apresentar pelo menos quatro formas diversas de grafia para tratar das mesmas instituições.

Após a busca na base de dados da BDTD, foram identificados 322 estudos. Já na pesquisa realizada no Pergamum do site de busca geral da $\mathrm{BCE} / \mathrm{UnB}$, foram obtidas 44 obras. Cumpridos os critérios de exclusão, indicados no terceiro passo do Quadro 1, foram selecionadas 12 produções que estão disponibilizadas on-line na BDTD e 6 obras no site de consultas da BCE que estão acessíveis apenas no acervo físico da biblioteca. Desse modo, o conjunto de fontes é composto por um total de 18 produções, sendo 2 teses, 13 dissertações, 2 livros e 1 capítulo de livro. No Quadro 2, são apresentados os estudos selecionados.

Quadro 2 - Estudos sobre ensino da arte nas escolas-parque de Brasília no período de 1960 a 2017, em ordem cronológica crescente

\begin{tabular}{|l|l|c|l|c|}
\hline \multicolumn{1}{|c|}{ Autores } & \multicolumn{1}{|c|}{ Título } & $\begin{array}{c}\text { Base de } \\
\text { dados }\end{array}$ & \multicolumn{1}{|c|}{ Tipo } & Ano \\
\hline $\begin{array}{l}\text { DUARTE, Maria } \\
\text { de Souza }\end{array}$ & $\begin{array}{l}\text { Educação pela arte } \\
\text { numa cidade nova: o } \\
\text { caso de Brasília }\end{array}$ & BCE & Dissertação & 1982 \\
\hline $\begin{array}{l}\text { DUARTE, Maria } \\
\text { de Souza }\end{array}$ & $\begin{array}{l}\text { A educação pela arte: } \\
\text { o caso Brasília }\end{array}$ & BCE & Livro & 1983 \\
\hline
\end{tabular}




\begin{tabular}{|c|c|c|c|c|}
\hline Autores & Título & $\begin{array}{c}\text { Base de } \\
\text { dados }\end{array}$ & Tipo & Ano \\
\hline $\begin{array}{l}\text { COSTA, Claudia da } \\
\text { Silva }\end{array}$ & $\begin{array}{l}\text { Educação musical: } \\
\text { práticas avaliativas } \\
\text { e organização do } \\
\text { trabalho pedagógico }\end{array}$ & BCE & Dissertação & 1996 \\
\hline $\begin{array}{l}\text { LEMOS, Maria } \\
\text { Beatriz Miranda }\end{array}$ & $\begin{array}{l}\text { Manifestações de } \\
\text { resistência em } \\
\text { oficinas de fanfarra e } \\
\text { percussão }\end{array}$ & BCE & Dissertação & 1998 \\
\hline $\begin{array}{l}\text { WIGGERS, Ingrid } \\
\text { Dittrich }\end{array}$ & $\begin{array}{l}\text { Corpos desenhados: } \\
\text { olhares de crianças } \\
\text { de Brasília através da } \\
\text { escola e da mídia }\end{array}$ & BDTD & Tese & 2003 \\
\hline $\begin{array}{l}\text { PEREIRA, } \\
\text { Alessandro } \\
\text { Guimarães }\end{array}$ & $\begin{array}{l}\text { Arquitetura escolar: } \\
\text { notas comparativas } \\
\text { sobre projetos em São } \\
\text { Paulo e Brasília }\end{array}$ & BCE & Dissertação & 2007 \\
\hline $\begin{array}{l}\text { DUARTE, Hélio de } \\
\text { Queiroz; TAKIYA, } \\
\text { André (Orgs.) }\end{array}$ & $\begin{array}{l}\text { Escolas classe escola } \\
\text { parque }\end{array}$ & BCE & Livro & 2009 \\
\hline $\begin{array}{l}\text { MARTINS, Alice } \\
\text { Fátima }\end{array}$ & $\begin{array}{l}\text { O ensino de artes nas } \\
\text { escolas parque }\end{array}$ & BCE & $\begin{array}{l}\text { Capítulo de } \\
\text { livro }\end{array}$ & 2011 \\
\hline $\begin{array}{l}\text { VASCONCELOS, } \\
\text { Maria Paula de } \\
\text { Almeida }\end{array}$ & $\begin{array}{l}\text { Sonho, memória } \\
\text { e educação: a } \\
\text { construção do } \\
\text { brasiliense }\end{array}$ & BDTD & Dissertação & 2011 \\
\hline $\begin{array}{l}\text { RIBEIRO, Alvaro } \\
\text { Maurício Moura } \\
\text { Paz }\end{array}$ & $\begin{array}{l}\text { Produção cultural } \\
\text { infantil: práticas } \\
\text { corporais sob a ótica } \\
\text { de crianças }\end{array}$ & BDTD & Dissertação & 2012 \\
\hline $\begin{array}{l}\text { LEME, Deborah } \\
\text { Raquel Rosin } \\
\text { Delphino de } \\
\text { Moraes }\end{array}$ & $\begin{array}{l}\text { Conceituação e } \\
\text { desenvolvimento } \\
\text { da escola parque } \\
\text { em Brasília, Rio de } \\
\text { Janeiro, Salvador e } \\
\text { São Paulo }\end{array}$ & BDTD & Dissertação & 2013 \\
\hline $\begin{array}{l}\text { XAVIER, Cleber } \\
\text { Cardoso }\end{array}$ & $\begin{array}{l}\text { Escolas parque } \\
\text { de Brasília: uso } \\
\text { do laboratório de } \\
\text { informática pelos } \\
\text { professores de arte }\end{array}$ & BDTD & Dissertação & 2013 \\
\hline
\end{tabular}




\begin{tabular}{|c|c|c|c|c|}
\hline Autores & Título & $\begin{array}{l}\text { Base de } \\
\text { dados }\end{array}$ & Tipo & Ano \\
\hline $\begin{array}{l}\text { BEZERRA, } \\
\text { Veronica Gurgel }\end{array}$ & $\begin{array}{l}\text { Os professores de } \\
\text { instrumentos e suas } \\
\text { ações nas escolas } \\
\text { parque de Brasília: } \\
\text { uma pesquisa } \\
\text { descritiva }\end{array}$ & BDTD & Dissertação & 2014 \\
\hline SOUZA, Edilson & $\begin{array}{l}\text { Diálogos entre Anísio } \\
\text { Teixeira e Darcy } \\
\text { Ribeiro - o projeto } \\
\text { educacional de Brasília } \\
\text { (1960) e o programa } \\
\text { especial de educação } \\
\text { - I PEE Rio de Janeiro } \\
\text { (1980) }\end{array}$ & BDTD & Tese & 2014 \\
\hline $\begin{array}{l}\text { ARAÚJO, Ana } \\
\text { Maria }\end{array}$ & $\begin{array}{l}\text { Pedagogia teatral e } \\
\text { diversidade cultural } \\
\text { no contexto da escola } \\
\text { parque } 210 / 211 \\
\text { Norte - Brasília-DF }\end{array}$ & BDTD & Dissertação & 2016 \\
\hline $\begin{array}{l}\text { MARQUES, Olívia } \\
\text { Augusta Benevides }\end{array}$ & $\begin{array}{l}\text { Pequenos enredos } \\
\text { nas escolas parque de } \\
\text { Brasília: o que contam } \\
\text { as crianças sobre a } \\
\text { aula de música }\end{array}$ & BDTD & Dissertação & 2016 \\
\hline $\begin{array}{l}\text { ROCHA, Laryssa } \\
\text { Mota Guimarães }\end{array}$ & $\begin{array}{l}\text { Uma história da dança } \\
\text { em escolas de Brasília: } \\
\text { memórias da escola- } \\
\text { parque do período de } \\
1960 \text { a } 1974\end{array}$ & BDTD & Dissertação & 2016 \\
\hline $\begin{array}{l}\text { FIGUEIROAA, } \\
\text { Arthur de Souza }\end{array}$ & $\begin{array}{l}\text { Construção de laços } \\
\text { pelas experiências } \\
\text { com as escolas parque } \\
\text { de Brasília: a história } \\
\text { de vida de duas } \\
\text { professoras de música }\end{array}$ & BDTD & Dissertação & 2017 \\
\hline
\end{tabular}

Fonte: Elaboração própria.

Tal como previsto no passo 6 do Quadro 1, após a leitura e interpretação qualitativa dos estudos, foram elencados três eixos de análise que representam as concepções do ensino de arte nas escolas-parque de Brasília: a) o ensino de arte como referência de uma nova perspectiva pedagógica para a educação nacional; b) o ensino de arte como elemento entrelaçador de culturas e construtor de uma identidade para a cidade de Brasília; c) o ensino de arte como mediador para autoexpressão, liberdade, emancipação e resistência. 


\section{O ensino de arte como referência de uma nova perspectiva pedagógica para a educação nacional}

Duarte $(1982,1983)$ remonta a história dos anos iniciais da primeira escola-parque de Brasília, localizada na entrequadra 307/308 Sul, bem como os ideais para a educação da nova capital no que tange às experiências educativas mediante a arte. Por meio de uma investigação histórica, utilizando documentos oficiais, pessoais e depoimentos de professores, estudantes e artistas pioneiros, a pesquisadora descreve as duas primeiras décadas da capital e apresenta um pouco da relação da cidade com as atividades artísticas desenvolvidas nessa escola. Em seus relatos, Duarte evidencia a significância desse espaço não apenas para compreensão do ensino de arte, mas para a nova educação a que se aspirava no Brasil.

Acreditava-se que Brasília conseguiria romper com a educação convencional que vigorava no País e, ao mesmo tempo, seria o "marco zero" para uma educação progressista. Almejava-se um ensino democrático em que os filhos de operários e funcionários tivessem acesso às mesmas oportunidades e no qual a arte constituiria um dos elementos articuladores dessa nova sociedade. A escola-parque tornou-se, então, essencial para o projeto idealizado naquele período (Teixeira, 1961).

A fim de tornar viável essa proposta, o mentor das escolas-parque da capital não deixou escapar detalhes. É possível observar no Plano de Construções Escolares de Brasília a forma precisa com que Teixeira tratou os elementos dessa nova concepção educacional. A arquitetura dessas instituições, por exemplo, convergia para uma educação renovada em que a escola não fosse apenas um ensaio para a vida em sociedade, mas a própria vida com tempos e espaços de qualidade (Teixeira, 1961). Testificando essas minúcias, os estudos de Pereira (2007) apontam as influências do conceito de escola progressiva nas edificações das escolas-classe e das escolasparque de Brasília, demonstrando as contribuições desses espaços para a aprendizagem da criança e para o desenvolvimento social. Segundo o autor:

[...] ainda que os sistemas de salas de aula existam nestas propostas, mantendo-se alguma proximidade com a ideia de pan-óptico, a proposta geral para os edifícios foi a de permitir o aprendizado além dos espaços da sala de aula. (Pereira, 2007, p. 99).

Acerca dos ambientes idealizados para as escolas-parque, Pereira (2007) destaca o pavilhão da unidade da 307/308 Sul, que não possui paredes fixas, mas divisórias que podem ser removidas. Essa estrutura foi pensada para representar os preceitos modernos da arquitetura, bem como da própria pedagogia, possibilitando que as atividades artísticas fossem diversificadas e demonstrando, assim, relações entre criatividade e espaço físico. No que diz respeito a esse aspecto, pontua ainda que o espaço pode forjar a imposição do adulto sobre a criança, convertendo-se em uma simbologia do poder que um exerce sobre a outra. Dessa forma, romper com a estrutura da arquitetura escolar tradicional significaria alterar a relação da criança com o conhecimento e com o seu convívio social. 
Outro fator de destaque para a educação que se idealizava concerne à formação dos professores das escolas-parque de Brasília. Se a pretensão era um novo arranjo em que a arte fosse uma diretriz para experiências pedagógicas transformadoras, não seria apropriado conservar velhas práticas da docência acerca das atividades e conceituações artísticas. Nos relatos coletados por Duarte $(1982,1983)$, os professores pioneiros expressaram que as orientações eram constantes, que teriam recebido formação até mesmo no Centro Educacional Carneiro Ribeiro, em Salvador, mencionado anteriormente. Há de se destacar que, diferentemente desse centro escolar, que foi implantado em uma periferia de Salvador e atendia apenas crianças em situação de vulnerabilidade social, na capital do País as escolas-parque foram pensadas para oferecer oportunidades iguais a todos. Assim, independentemente de classe social, a criança teria uma formação que vislumbraria na arte - além das atividades de recreação, esporte e lazer - a possibilidade de experiências para a constituição de um ser humano integral, apto a viver na complexidade da civilização técnica e industrial (Teixeira, 1959).

Segundo Duarte e Takiya (2009), arquiteto contemporâneo de Teixeira, o educador brasileiro tinha grande apreço pelas atividades artísticas infantis. Sua admiração foi estimulada pelas visitas aos Estados Unidos, onde conheceu o sistema platoon de Detroit - Brady School. A organização escolar platoon, ou de pelotões, constituiu-se como uma solução para contemplar os aspectos físicos e curriculares almejados para uma educação progressista, "tendo ainda como objetivo proporcionar uma diversidade de ensino, enriquecida com novas e interessantes matérias" (Duarte; Takiya, 2009, p. 94). Nesse sistema, arte, música, desenho, trabalho manual e ciência conferiam ao currículo um elevado nível. Segundo o autor, Teixeira passou a considerar que essa estrutura atenderia à reforma educacional que o Brasil necessitava e que a arte, atividade criadora e inerente da natureza humana, poderia ser um aporte para transformação e recuperação do valor social da escola, sem ser considerada um privilégio dos filhos das famílias da elite.

Martins (2011) destaca que, além da inspiração no modelo platoon e da reconhecida influência que Dewey exerceu em seu pensamento pedagógico, Teixeira orientou-se ainda na filosofia das Escolinhas de Arte do Brasil, lideradas principalmente pela figura de Augusto Rodrigues. De acordo com a autora, para Rodrigues a atividade artística poderia ser compreendida como uma forma de expressão do sentimento humano, não havendo para isso fórmulas excepcionais, apenas a possibilidade de potencializar aquilo que é uma experiência comum a todos.

Desse modo, podemos entender que, no ideário das escolas-parque de Brasília, o ensino de arte estava pautado na sensibilização e na produção de conhecimento por meio das diversas linguagens artísticas, por exemplo, a música, o teatro, a dança e as artes visuais. "A ênfase não estava no ensino de determinado trabalho ou técnica, mas na oportunidade assegurada aos alunos de aprender e produzir, atuando coletivamente" (Martins, 2011, p. 242). Essa perspectiva contempla a fusão dos saberes adotados por Teixeira e também aponta a inventividade e a autonomia do seu projeto. 
Trata-se aqui o termo o outro dentro de uma compreensão fenomenológica da filosofia em que há o "deslocamento de uma concepção metafísica da identidade para uma concepção enraizada nos contextos plurais do mundo da vida, que se vê diante da alteridade, num eu que é atravessado pelo outro" (Hermann, 2014, p. 42).
Corroborando esse pensamento, Leme (2013) demonstra que, embora não tenha se aprofundado nas concepções de Dewey sobre a arte como experiência, Teixeira atribuía relevância à educação artística, tendo como referência os pressupostos da livre expressão e da experimentação difundidos por Herbert Read (1893-1968). Read foi importante influenciador das Escolinhas de Arte e era conhecedor da visão deweyana sobre arte como experiência. Segundo Barbosa (2011), apesar de Teixeira não ter alcançado essas concepções elaboradas por Dewey, sua defesa pelas atividades manuais esteve imbricada na arte, conferindo-lhe um caráter de flexibilidade curricular que não se pautava no utilitarismo, mas na elaboração de hábitos para a socialização dos estudantes e da comunidade. No tocante a isso, Ribeiro (2012) observa que a forma autêntica como o ensino de arte foi concebido nas escolas-parque de Brasília permitiu aos estudantes construírem e transformarem suas relações com o saber mediante experiências estéticas.

Nessa perspectiva, Vasconcelos (2011) confere às escolas-parque de Brasília uma das expressões mais significativas do plano de Teixeira. Ao tentar remontar aos primeiros anos da educação do Distrito Federal (1956-1964), a pesquisadora percebe que as atividades propostas nesses espaços educativos não se referiam só ao desenvolvimento de práticas manuais ou intelectuais, mas à consubstanciação da potencialidade humana aprimorada por meio da arte. Vasconcelos (2011) aponta ainda que a concepção metodológica para o ensino de arte nesses espaços não fomentava a exclusividade de correntes artísticas, mas buscava na diversidade do trabalho pedagógico uma aprendizagem prazerosa. As conceituações de arte para essas escolas não carregavam em si a centralidade do processo artístico das crianças, mas se estendiam em torno de experiências que esse momento era capaz de proporcionar.

Dessa maneira, compreende-se que a arte era entendida como um elemento unificador, passível de atuar no devir social, nas relações do indivíduo com o outro, ${ }^{2}$ com a natureza, com a sua subjetividade e com os conhecimentos elaborados. Esse aspecto condizia com a construção de uma nova referência pedagógica para a educação nacional e atendia a uma vicissitude brotada particularmente no contexto de Brasília. A nova capital era considerada uma cidade cosmopolita, com pessoas de culturas diversas, que chegavam de inúmeros pontos do País e do mundo e aos poucos se aproximavam dos que já estavam nos arredores. Muitos não tinham parentela, histórias ou lembranças constituídas naquele chão vermelho do quadrilátero. Assim, podemos dizer que surgiu uma necessidade no ensino de arte das escolas-parque de Brasília que talvez não tenha sido previamente idealizada: a de se entrelaçar as diversas culturas dos estudantes e docentes advindos de diferentes localidades. Os textos analisados apontam ainda que havia a necessidade de se construir uma identidade para Brasília. Nesse sentido, a arte nas escolas-parque teria papel fundamental. 


\section{O ensino de arte como elemento entrelaçador de culturas e construtor de uma identidade para a cidade de Brasília}

Quando Teixeira idealizou as escolas-parque de Brasília, ele não as pensou de modo isolado, mas como parte constitutiva de um centro elementar. Nesse cenário, a infância fora pensada sob um novo ponto de vista, diferente daquele que a educação tradicional vinha praticando, ou seja, com base na repetição e na seleção de métodos e conteúdos que pouco dialogavam com a vida. As concepções que nortearam o Plano de Construções Escolares de Brasília, e consequentemente o projeto das escolas-parque, estavam conectadas com uma tendência moderna que se alavancava junto aos ideais democráticos e progressistas da sociedade industrial. As convicções que se pretendia difundir no País deveriam reverberar pelos diversos setores sociais, desde a política e a economia até a educação, a saúde e o lazer, por exemplo. Teixeira (1961) entendia que a sociedade progressista não poderia se desenvolver sem preservar os traços de seus aspectos sociais e humanos, seu contexto e sua história. O educador compreendia que era dever da elite de cada tempo conduzir de maneira saudável o progresso do País.

Foi no auge dessas aspirações que Brasília se edificou como a capital brasileira da modernidade intelectual e arquitetônica. Souza (2014, p. 86) destaca que a cidade foi organizada pelo princípio das chamadas "unidades de vizinhança", agrupadas em superquadras compostas não apenas por blocos residenciais, mas também por:

[...] todos os equipamentos necessários para a vida em comunidade: o comércio local, a igreja, o clube, o cinema, a biblioteca, o posto de saúde, a delegacia de polícia, correios e outras facilidades colocadas à disposição dos seus habitantes. (Souza, 2014, p. 86).

Entretanto, apesar dos esforços no planejamento da cidade, esse arranjo foi acompanhado de certa frieza. Duas grandes asas de asfalto cortavam o cerrado entre o sul e o norte, blocos de concreto e um céu com tons de azul e cinza fundiam-se à ideia da novidade, tal como o passado dava lugar a um futuro enigmático. Nesse cenário, a população da nova capital passa a se entrelaçar na diversidade das culturas de cada família ou indivíduo pioneiro e, por conseguinte, a construir uma identidade para Brasília. De acordo com Vasconcelos (2011), os aspectos identitários da nova capital se consolidaram a partir dessa coletividade cultural que se engendrou, principalmente, em função da orientação educacional elaborada para a cidade.

Segundo Duarte (1983), a primeira escola-parque de Brasília foi por muito tempo um ponto de construção das narrativas sociais e culturais da cidade. No auditório da escola, aconteciam festivais nos quais a comunidade escolar podia se encontrar, conhecer-se e perceber a presença do outro. O professor pioneiro Hélio Lopes dos Santos recorda que naquela época "ainda vivíamos o sonho de termos vários segmentos da sociedade misturados, na mesma sala o filho do senador, do ministro, do motorista" 
(Duarte, 1983, p. 96). Essa característica agregava à escola-parque a necessidade de entrelaçar as culturas, os diferentes costumes regionais ou nacionais e ainda os diversos níveis socioeconômicos dos estudantes.

Rocha (2016) reconhece na primeira escola-parque de Brasília um espaço que privilegiou o desenvolvimento de atividades culturais. A autora analisou fotografias concernentes às atividades pedagógicas de dança entre os anos de 1960 e 1974. Observou que a dança representou mais do que a expressão de uma linguagem artística, manifestando também um corpo compreendido em sua dimensão sócio-histórico-cultural, que influenciou e foi influenciado pelo outro em seus diversos aspectos. A partir dessa percepção, é possível apreender que essas atividades representaram momentos de produções culturais, pois as crianças, assim como toda a comunidade escolar, ensinavam, aprendiam, trocavam vivências, apropriavam-se delas e (re)elaboravam suas experiências por meio dessa linguagem artística. Na dinâmica entre as significações, as apreciações e o estranhamento do diverso, tecia-se também uma identidade peculiar para a capital.

De acordo com Xavier (2013), a valorização e a preservação do patrimônio são recorrentes no trabalho pedagógico das escolas-parque. A relação dos estudantes com a cidade enquanto um outro cultural e o entendimento da própria capital como representação artística continuam a ser elementos importantes no ensino de arte nessas instituições, constituindo e (res)significando a identidade da cidade, uma vez que os indivíduos não são atores passivos nessa construção social.

Araújo (2016) atribui à diversidade das linguagens artísticas desenvolvidas na Escola-Parque 210/211 Sul um aporte para as relações culturais e identitárias. A autora entende que qualquer espaço escolar pode oferecer essa oportunidade, contudo, essa instituição é capaz de ampliá-la, pois as diversidades despertam o reconhecimento das diferenças representadas nos indivíduos mediante suas práticas sociais, seus conhecimentos e suas memórias históricas ou espaciais.

Desse modo, as escolas-parque da capital, por meio das atividades artísticas, constituem-se como espaço de entrelaços culturais, de reconhecimento do outro, bem como de criação de uma identidade cultural, educacional e histórica para a cidade de Brasília. Os estudos evidenciam ainda que essas características são provenientes e fomentadoras de aspectos formativos peculiares, que permitem engendrar mais um núcleo de análise, descrito a seguir.

\section{O ensino de arte como mediador de autoexpressão, liberdade, resistência e emancipação}

Nascidas como símbolos educativos de uma era moderna, em terra de gente diversa, que aprendeu a equilibrar tradições e inovações culturais para ser cidadão do mundo, as escolas-parque de Brasília refletem a ousadia de seu idealizador e daqueles que acreditaram na potencialidade de sua 
proposta. Isso pode ser visto nas pesquisas que demonstram o ensino de arte como um mediador de autoexpressão, liberdade, resistência e emancipação.

Os trabalhos de Costa (1996) e Lemos (1998) apresentam as oficinas de fanfarra e de percussão, vivenciadas em meados da década de 1990, como relevantes para a compreensão desse quadro. As autoras observam que naquele período, apesar de as oficinas serem consideradas os "carroschefes" das escolas-parque, houve muita dificuldade quanto aos aspectos de musicalização, devido ao caráter de repetição utilizado como metodologia e à precariedade dos instrumentos musicais. Entretanto, mesmo com essas adversidades, as crianças se predispunham a participar das atividades com entusiasmo, era perceptível o "prazer corporal atrelado ao ato de tocar-ouvir música" (Lemos, 1998, p. 61). Outro aspecto discutido nesses estudos diz respeito às apresentações finais elaboradas como motivação e avaliação para os estudantes nessas oficinas. As pesquisadoras depreendem que, apesar de haver críticas no campo da pedagogia do ensino de arte acerca das atividades destinadas a um resultado, esse, por vezes, é o caminho viável para que as crianças tenham experiências artísticas no espaço da escola. Assim, as escolas-parque são percebidas como um campo de possibilidades criativas, de experimentação de situações da "vida vivida", de liberdade e autoexpressão. Nesse sentido, autoexpressão e liberdade estão imbricadas, pois só é possível observar que se expressa aquele que tem liberdade em seus movimentos, pensamentos, desejos e propósitos (Dewey, 2011).

Wiggers (2003) destaca a representatividade das escolas-parque no que tange ao desenvolvimento das experiências em arte, uma vez que essas experiências diferem das práticas fragmentadas comumente exploradas nas escolas convencionais como momentos de lazer e distração; a autora também reconhece o viés libertador dessa área do conhecimento. De acordo com Wiggers (2003, p. 95), por meio da atividade artística, "as crianças percebem e recriam aquelas noções de corpo difundidas pelo sistema cultural, principalmente a escola e a mídia". Desse modo, atribui ao desenho da figura humana um lugar de destaque, porque é nessa representatividade que o próprio corpo se elabora, personifica-se, cria e experimenta realidades múltiplas de si mesmo. O desenho, segundo Wiggers (2003), é ao mesmo tempo atividade artística e brincadeira. Na escola-parque pesquisada, o desenho é um elemento de resistência às figurações da indústria cultural, o que fica evidenciado pelo desafio da representatividade entre aquilo que se vê e o que se sabe sobre si e sobre o mundo. Nessa perspectiva, a arte no contexto da escolarização pode ser entendida como atividade fundamental para que o indivíduo consiga romper com os modelos que lhe são atribuídos na sociedade e criar, então, alternativas para a constituição de subjetividade e corporeidade.

No que concerne às escolas-parque de Brasília, observa-se que essa resistência se desdobra em pelo menos dois aspectos: a resistência no seu sentido formativo e a do próprio espaço físico. No que tange ao primeiro ponto, nota-se que ocorre sobretudo pelas memórias históricas que os professores conhecem dessas instituições. Ainda que os docentes não tenham a dimensão de toda a trajetória das escolas-parque em que atuam, 
constroem seus significados por meio das narrativas e da cultura escolar. Como consequência, mesmo com a falta de estrutura, o espaço físico também tem resistido (Xavier, 2013).

Segundo Leme (2013), esses conflitos entre compreender os ideais pedagógicos e manter o espaço físico são quase inerentes à inauguração da primeira escola-parque da capital. De acordo com a autora, desde a edificação da instituição em Brasília, percebem-se tentativas de desfiguração do projeto original não apenas no que concerne aos objetivos dos aspectos formativos dos indivíduos, mas também à estrutura das construções e à utilização dos espaços arquitetônicos, que se relacionam diretamente com as aprendizagens.

Apesar de as escolas-parque de Brasília terem sobrevivido a esquecimentos, muito do ideário de Teixeira se modificou. Não se trata mais de uma educação em período integral para a formação global dos sujeitos, como preconizava o Plano de Construções Escolares de Brasília. Essa ruptura reverbera nas diferentes linguagens artísticas trabalhadas. Bezerra (2014), em uma pesquisa sobre os professores de instrumentos musicais e suas ações nas escolas-parque de Brasília, percebe que muitas das conceituações e situações vividas nesses espaços não apresentam debates epistemológicos. A autora põe em questionamento situações do cotidiano pedagógico e suas implicações, por exemplo, a insuficiência de violões para as aulas de instrumentos de cordas, em que as crianças se encontram em diferentes níveis de aprendizagem.

Essas indagações levam a refletir sobre as consequências das modificações ocorridas nas escolas-parque de Brasília no tocante à potencialidade formativa do ensino de arte. Segundo Bezerra (2014), nem mesmo o critério da formação específica de cada docente tem sido respeitado. Devido à falta de condições de exercer um trabalho voltado para a aprendizagem das técnicas musicais, os professores de música optam por oferecer oficinas de dança e musicalização. Na contramão, professores com formação em outras linguagens artísticas assumem as aulas dessa área pautados em suas vivências e experiências, mas não em suas formações iniciais ou continuadas. Isso reforça a problemática da polivalência no ensino de arte, quando um especialista leciona em diversas linguagens artísticas (Vasconcelos; Devechi, 2018).

De acordo com Bezerra (2014), os docentes desenvolvem articulações e estratégias para lidar com os desafios que se sobrepõem aos aspectos formativos do ensino de arte nas escolas-parque de Brasília. Conforme a autora, é na interação dos saberes e nas trocas de experiências e materiais que os professores alegam construir suas identidades como docentes das escolas-parque, além de constituírem um modo de resistir e se fortalecer coletivamente.

Apesar das particularidades que as produções acadêmicas demonstram acerca do trabalho pedagógico desenvolvido em cada escola-parque de Brasília, existem alguns consensos nas concepções do ensino de arte descritas, até mesmo nas atividades que os professores acreditam executar de maneira mais isolada na rede de ensino. Nota-se que as ideias 
de experimentação, vivências, sensibilização e familiarização com a arte perpassam a maioria dos estudos e são apontadas como caminhos que conduzem os estudantes ao desenvolvimento de autoexpressão e liberdade.

É importante ressaltar que muitos entendimentos acerca do ensino de arte nas escolas-parque de Brasília advêm das próprias crianças e adolescentes que frequentaram esses espaços. São eles, juntamente com o corpo docente, que produzem os sentidos práticos dos ideais, projetos e documentos norteadores. A respeito disso, Figueirôa (2017) evidencia o entrelaço entre as vidas de crianças e professores nas escolas-parque de Brasília e destaca quão significativas são as vivências nessas instituições, a ponto de inspirarem estudantes a se tornarem docentes nessas unidades. Marques (2016), em sua pesquisa (auto)biográfica com crianças das escolas-parque, revela que elas concebem o ensino de arte representado nas atividades musicais como um momento de liberdade, em que podem expressar seus entusiasmos e esperanças. Na visão das crianças, a escola é um parque de brincadeiras, tal como sugere o nome da instituição. Isso demonstra quanto as experiências artísticas estimulam a sensibilidade infantil.

Assim, não obstante algumas dificuldades e instabilidades interpostas ao ensino de arte nas escolas-parque de Brasília, é possível afirmar que essas instituições não apenas cumprem ao longo do tempo seu objetivo, mas se empenham também em fazer com que as atividades artísticas transcendam o próprio campo da arte enquanto técnica, contribuindo significativamente com a formação dos estudantes e reverberando a utopia de Teixeira na história da educação brasileira.

\section{Considerações finais}

A existência das escolas-parque de Brasília é marcada por diversas histórias, construídas não apenas por diretrizes que preconizaram sua edificação arquitetônica e pedagógica, mas também pelas memórias dos professores pioneiros e pelas narrativas de estudantes e pesquisadores, ainda curiosos por essa invenção pouco assimilada na educação brasileira. Por meio dos textos que compuseram esta revisão sistemática, buscou-se examinar as concepções do ensino de arte nas escolas-parque de Brasília. Cada produção bibliográfica se coloca como uma peça fundamental desse exercício e ampara o (re)conhecimento do ensino de arte como aporte de uma educação integral, que vislumbra indivíduos mais críticos e sensíveis, aptos a viverem em um mundo complexo.

As concepções das primeiras experiências do ensino de arte nas escolas-parque da capital tinham por objetivo fundamentar e disseminar uma nova perspectiva educacional, que surgia junto ao sonho de uma nação democrática. Na modernidade, era preciso construir uma nova sociedade, dotada de ascensão cultural e de indivíduos autônomos perante a vida. As atividades artísticas contribuiriam para a formação de sujeitos integrais, capazes de atuar nas idiossincrasias do período industrial, sem perder sua 
perspicácia sensível e intelectual, tal como preconizava Teixeira. Assim, o ensino de arte nas escolas-parque não se pautava nas técnicas, mas na interação contínua dos estudantes com os objetos, as produções artísticas e os contextos que lhes abririam outras possibilidades de aprendizagens, inclusive na relação com o espaço arquitetônico pensado para essas instituições.

A conjuntura dessa invenção de Teixeira acabou por cooperar para entrelaçar as diversidades culturais, uma vez que os moradores e estudantes da capital eram advindos das diferentes regiões do País e do mundo. Nesse sentido, as atividades artísticas criavam um espaço de encontro de diversas culturas. Não seria possível gerar outros costumes de vida, sem considerar as diferenças que eclodiam naquele momento. Diante disso, o ensino de arte das escolas-parque também ajudou na construção de uma identidade para Brasília. Essa escola se forjou como espaço para (res)significar os olhares mediante a arquitetura e a desenvoltura política, econômica, histórica, cultural, social e estética da cidade. Reconhecer as diversidades culturais que permeiam a construção da população de Brasília e daqueles que de alguma forma se relacionam na contemporaneidade com a cidade ainda é um objetivo comumente relatado nas concepções do ensino de arte das escolas-parque.

Em consonância com o projeto humanista de Teixeira para a educação da nova capital, as concepções do ensino de arte das escolas-parque se revelam em aspectos considerados formativos, como a autoexpressão, a liberdade, a resistência e a emancipação. Tais referências tangenciam as produções em diferentes momentos da história dessas instituições. Conforme relatam docentes, egressos e estudiosos, o que se percebe é que, ao seu modo, as escolas-parque conseguiram ao longo do tempo um movimento sincronizado entre esses elementos. Em outras palavras, ao tempo em que o indivíduo se expressa, ele tem liberdade, emancipa-se e resiste.

Por fim, as compreensões acerca do ensino de arte nas escolas-parque de Brasília ajudam a (re)construir a história do ensino de arte na capital brasileira, a (re)pensar os trabalhos pedagógicos experimentados nesses espaços e a reinventar junto à utopia de Teixeira possibilidades para essas instituições nos dias atuais, valorizando a arte como uma área do conhecimento fundamental para a formação de seres humanos íntegros e ativos, aptos a viver em um mundo complexo. Posto isso, sugere-se a continuidade de estudos de revisão de literatura que deem ênfase às reflexões relativas às transmutações das concepções da arte nas escolas-parque. 


\section{Referências}

ARAÚJO, A. M. Pedagogia teatral e diversidade cultural no contexto da escola parque 210/211 Norte. 2016. 120 f., il. Dissertação (Mestrado em Educação) - Faculdade de Educação, Universidade de Brasília, Brasília, 2016.

BARBOSA, A. M. John Dewey e o ensino da arte no Brasil. 7. ed. São Paulo: Cortez, 2011.

BEZERRA, V. G. Os professores de instrumentos e suas ações nas escolas parque de Brasília: uma pesquisa descritiva. 2014. 194 f., il. Dissertação (Mestrado em Música) - Instituto de Arte, Universidade de Brasília, Brasília, DF, 2014.

CARDOSO, S. F. Diários de viagem de Anísio Teixeira: razões e sentidos de uma escrita de "si" e do "outro". Revista Brasileira de Estudos Pedagógicos, Brasília, DF, v. 94, n. 236, jan./abr. 2013.

CARDOSO, V. D. et al. Professores iniciantes: análise da produção científica referente a programas de mentoria (2005-2014). Revista Brasileira de Estudos Pedagógicos, Brasília, DF, v. 98, n. 248, p. 181-197, jan./abr. 2017.

COSTA, C. S. Educação musical: práticas avaliativas e organização do trabalho pedagógico. 1996. 95 f. Dissertação (Mestrado em Educação) Faculdade de Educação, Universidade de Brasília, Brasília, DF, 1996.

DEWEY, J. Arte como experiência. Tradução de Vera Ribeiro. São Paulo: Martins Fontes, 2010.

DEWEY, J. Experiência e educação. Tradução de Renata Gaspar. 2. ed. Petrópolis: Vozes, 2011.

DUARTE, H. de Q.; TAKIYA, A. (Org.). Escolas classe escola parque. 2. ed. São Paulo: FAUUSP, 2009.

DUARTE, M. S. A educação pela arte: o caso Brasília. Brasília, DF:

Thesaurus, 1983.

DUARTE, M. S. Educação pela arte numa cidade nova: o caso de Brasília. 1982. 222 f. Dissertação (Mestrado em Educação) - Faculdade de Educação, Universidade de Brasília, Brasília, DF, 1982.

FIGUEIRÔA, A. S. Construção de laços pelas experiências com as escolas parque de Brasília: a história de vida de duas professoras de música. 2017. 144 f., il. Dissertação (Mestrado em Música) - Instituto de Artes, Universidade de Brasília, Brasília, DF, 2017. 
HERMANN, N. Ética \& educação: outra sensibilidade. Belo Horizonte: Autêntica, 2014.

LEME, D. R. R. D. M. Conceituação e desenvolvimento da escola parque em Brasília, Rio de Janeiro, Salvador e São Paulo: de 1931 a 2013.

2013.154 f. Dissertação (Mestrado em Arquitetura e Urbanismo) Universidade Presbiteriana Mackenzie, São Paulo, 2013.

LEMOS, M. B. M. Manifestações de resistência em oficinas de fanfarra e percussão. 1998. 97 f. Dissertação (Mestrado em Educação) - Faculdade de Educação, Universidade de Brasília, Brasília, DF, 1998.

MARQUES, O. A. B. Pequenos enredos nas escolas parque de Brasília o que contam as crianças sobre a aula de música. 2016. 104 f., il. Dissertação (Mestrado em Música) - Universidade de Brasília, Brasília, DF, 2016.

MARTINS, A. F. O ensino de artes nas escolas parque. In: PEREIRA, E. W. (Org.). Nas asas de Brasília: memórias de uma utopia educativa (1956-1964). Brasília, DF: Universidade de Brasília, 2011. p. 231-251.

PEREIRA, A. G. Arquitetura escolar: notas comparativas sobre projetos em São Paulo e Brasília. 2007. 158 f. Dissertação (Mestrado em Arquitetura e Urbanismo) - Universidade de Brasília, Brasília, DF, 2007.

RAPLEY, T.; REES, G. Collecting documents as data. In: FLICK, U. (Ed.) The sage handbook of qualitative collection. London: Sage, 2018. p. 378-391.

RIBEIRO, Á. M. M. P. Produção cultural infantil: práticas corporais sob a ótica de crianças. 2012. 99 f., il. Dissertação (Mestrado em Educação Física) - Faculdade de Educação Física, Universidade de Brasília, Brasília, DF, 2012.

ROCHA, L. M. G. Uma história da dança em escolas de Brasília: memórias da escola-parque do período de 1960 a 1974. 2016. 158 f., il. Dissertação (Mestrado em Educação Física) - Faculdade de Educação, Universidade de Brasília, Brasília, DF, 2016.

SONI, G.; KODALI, R. A critical analysis of supply chain management content in empirical research. Business Process Management Journal, [S.l.], v. 17, n. 2, p. 238-266, Apr. 2011.

SOUZA, E. Diálogos entre Anísio Teixeira e Darcy Ribeiro: o projeto educacional de Brasília (1960) e o programa especial de educação (I PEE) Rio de Janeiro (1980). 2014. 86 f. Tese (Doutorado em Educação) Faculdade de Educação, Universidade do Estado do Rio de Janeiro, Rio de Janeiro, 2014. 
TEIXEIRA, A. Centro Educacional Carneiro Ribeiro. Revista Brasileira de Estudos Pedagógicos, Rio de Janeiro, v. 31, n. 73, p. 78-84, jan./mar. 1959.

TEIXEIRA, A. Plano de construções escolares de Brasília. Revista Brasileira de Estudos Pedagógicos, Rio de Janeiro, v. 35, n. 81, p. 195-199, jan./mar. 1961.

TRANFIELD, D.; DENYER, D.; SMART, P. Towards a methodology for developing evidence-informed management knowledge by means of systematic review. British Journal of Management, [S.l], v. 14, n. 3, p. 207-222, Sept. 2003.

VASCONCELOS, M. P. de A. Sonho, memória e educação: a construção do brasiliense. 2011. 149 f. Dissertação (Mestrado em Educação) Faculdade de Educação, Universidade de Brasília, Brasília, DF, 2011.

VASCONCELOS, R. L.; DEVECHI, C. P. V. A arte-educação no ensino médio: desafios à formação estética. Educação, v. 43, n. 4, p. 741-756, out./dez. 2018.

WIGGERS, I. D. Corpos desenhados: olhares de crianças de Brasília através da escola e da mídia. 2003. 326 f., il. Tese (Doutorado em Educação) - Universidade Federal de Santa Catarina. Florianópolis, 2003.

XAVIER, C. C. Escolas parque de Brasília: uso do laboratório de informática pelos professores de arte. 2013. 150 f. Dissertação (Mestrado em Arte) - Instituto de Arte, Universidade de Brasília, Brasília, DF, 2013.

Recebido em 2 de outubro de 2019.

Aprovado em 11 de agosto de 2020.

Este é um artigo de acesso aberto distribuído nos termos da licença Creative Commons do tipo BY-NC. 